\title{
Human NINEIN polymorphism at codon 1111 is associated with the risk of colorectal cancer
}

\author{
YUKIKO YASUDA $^{1 *}$, AKIKO SAKAI $^{1 *}$, SACHIO ITO $^{1}$, KAORI SASAI $^{1}$, AKISADA ISHIZAKI $^{1}$, \\ YOSHIYA OKANO $^{1}$, SEITO KAWAHARA ${ }^{1}$, YOSHIMI JITSUMORI ${ }^{1}$, HIROMASA YAMAMOTO ${ }^{2}$, \\ NAGAHIDE MATSUBARA ${ }^{3}$, KENJI SHIMIZU ${ }^{1}$ and HIROSHI KATAYAMA ${ }^{1}$ \\ Departments of ${ }^{1}$ Molecular Oncology, ${ }^{2}$ General Thoracic Surgery and Breast and Endocrinological Surgery, \\ and ${ }^{3}$ Gastroenterological Surgery, Okayama University Graduate School of Medicine, \\ Dentistry and Pharmaceutical Sciences, Okayama 700-8558, Japan
}

Received February 3, 2020; Accepted April 7, 2020

DOI: 10.3892/br.2020.1352

\begin{abstract}
NINEIN serves an essential role in centrosome function as a microtubule organizing center, and in the reformation of the interphase centrosome architecture following mitosis. In the present study, the association between NINEIN Pro1111Ala (rs2236316), a missense single nucleotide polymorphism, and the risk of colorectal cancer (CRC), related to smoking and alcohol consumption habits in 200 patients with CRC and 1,141 cancer-free control participants were assessed in a case-control study performed in Japan. The results showed that the NINEIN Ala/Ala genotype compared with the Pro/Pro genotype was significantly more associated with an increased risk of $\mathrm{CRC}$, and the males with the Ala/Ala genotype exhibited a significantly increased risk of CRC compared with those with Pro/Pro and Pro/Ala genotypes. Stratified analyses of the Ala/Ala genotype with CRC risk further showed an increased association in never/light drinkers ( $<23 \mathrm{~g}$ of ethanol/day), in male never/light drinkers and in male patients with rectal cancer. These findings suggest that the genetic variant of the NINEIN Pro1111Ala polymorphism has a significant effect on CRC susceptibility in the Japanese population.
\end{abstract}

\section{Introduction}

Colorectal cancer (CRC) is a common malignancy with high incidence and mortality rates both in male and female patients

Correspondence to: Dr Akiko Sakai or Dr Hiroshi Katayama, Department of Molecular Oncology, Okayama University Graduate School of Medicine, Dentistry and Pharmaceutical Sciences, Shikata-cho 2-5-1, Kita-ku, Okayama 700-8558, Japan

E-mail: sakak23@md.okayama-u.ac.jp

E-mail: hkatayama@cc.okayama-u.ac.jp

*Contributed equally

Key words: NINEIN, centrosome, single nucleotide polymorphism, colon cancer, tumor susceptibility in Japan, although the overall 5-year survival rate is relatively high $(95.5,88.5$ and $76.5 \%$ for patients with stages I, II and III CRC, respectively) (1). At present, the implementation of CRC population screening has contributed to the reduction of morbidity and mortality rates, which indicates that the earlier the CRC diagnosis is confirmed, the more effective and easier the therapeutic treatment to patients will be, resulting in favorable prognoses. Among the different epidemiological factors, cigarette smoking and alcohol consumption have been known to be associated with a higher risk of CRC (2-6). In particular, alcohol consumption shows a significantly higher association with CRC in Japanese individuals compared with Western populations (7).

CRC tumor location has been hypothesized to have important implications in clinical and pathological aspects. The left side of the colon, consisting of the descending colon, the sigmoid colon and the rectum, has a different embryonic origin than the right side of colon, which consists of the cecum, the ascending colon and the transverse colon $(8,9)$. Therefore, the two sides of the colon have discrete physiological characteristics and molecular backgrounds. Recent advances in molecular biology have revealed that CRC is classified into two, mutually exclusive, distinct types based on the genomic instability. Microsatellite instability (MIN) occurs in the proximal segments (right colon), and chromosomal instability (CIN) arises in the distal segments (left colon and the rectum) of the large bowel, respectively $(8,9)$. The proximal and distal regions have different and distinct embryological origins, which subsequently show different anatomical and functional structures and properties, respectively (8). The CIN pathway is considered the traditional colon cancer progression pathway, in which the molecular model of the Vogelstein's adenoma-to-carcinoma sequence, characterized by a progressive accumulation of genetic alterations, such as mutations in $K R A S, A P C, D C C$, TP53 with a loss of heterozygosity, and global hypomethylation is relevant (10). MIN is another mutator pathway, characterized by the dysfunctional mismatch repair genes and a secondary mutation of the genes with coding microsatellites through the methylation of promoters $(9,10)$. The expression of cancer-associated genes may be altered either by aberrant DNA hypomethylation of global DNA, typically observed 
in the CIN pathway, or by hypermethylation of promoters, observed in the MIN pathway (10). Furthermore, dysregulation of centrosome function or chromosomal segregation may predispose patients to CIN-related cancer development (11).

NINEIN is a centrosomal protein, identified as the microtubules' minus-end capping, centriole position and an anchoring protein. NINEIN serves essential roles in the formation of the mitotic spindle, cell polarity and cell locomotion (12-16). It contains an N-terminal potential GTPase/GTP-binding site, a large coiled-coil domain with four leucine zippers, C-terminal oligomerization and a GSK3 $\beta$-binding domain $(14,17)$. The significance of the NINEIN coiled-coil II domain, co-localizing with $\gamma$-tubulin and centrin at the centrosome, is associated with a centrosomal targeting signal, regulating signal and phosphorylation sites (13). NINEIN has been suggested to contribute to the complex centrosome architecture and regulate centrosome asymmetry for controlling cell polarity during the cell cycle (13). Although some missense mutations and allelic variants in the NINEIN gene are reportedly associated with microcephalic primordial dwarfism disorder, a phenotype associated with a severe form of human growth failure and shared by the Seckel syndrome $(18,19)$, or spondyloepimetaphyseal dysplasia (20), their association with CRC remains to be clarified.

A number of single nucleotide polymorphism in genes controlling centrosome function has been shown to be associated with an increased risk of developing and promoting a range of different types of cancer $(21,22)$; however, the value of single nucleotide polymorphisms of the NINEIN gene have not been assessed yet, to the best of our knowledge. In the present study, the effects of the NINEIN Pro1111Ala (rs2236316) polymorphism on the risk of CRC and its association with cigarette smoking, alcohol consumption and tumor position of CRC in the Japanese population were assessed.

\section{Materials and methods}

Study population. The cases of 200 Japanese patients with primary CRC whose tumors were operated on and histologically confirmed at Okayama University Hospital (Okayama, Japan) between 1994-2005 (specific months unavailable) were retrospectively analyzed. The clinical and histopathological classification of the tumors was performed according to the criteria of the Union for International Cancer Control Tumor-Node-Metastasis Classification of Malignant Tumors, 6th edition, 2002 (23). There were two hereditary CRC cases (one case of hereditary non-polyposis CRC and one case of familial adenomatous polyposis), and one case of ulcerative colitis-associated with CRC, all of which were also included in the analysis. For the controls, 1,141 Japanese patients consisting of two groups: 227 Outpatients without cancer who visited Kusaka Hospital at Okayama in 2005, and 914 healthy individuals who visited Junpukai Health Care Center at Okayama for medical check-up in 2009. The median age of the 200 Japanese patients with colorectal cancer was 64 years (age range, 23-89 years), and consisted of 115 males and 85 females. The median age of 1,141 individuals in the control group was 55 years (age range, 32-94 years), and consisted of 675 males and 466 females. The median age of all study participants was 56 (age range, 23-94).
The age, sex, personal and family medical histories, and smoking and drinking history of the subjects were obtained from interviews and medical questionnaire records. The smoking status was assessed by pack-year equivalents [(cigarettes per day/20)x(smoking years)]. The classification of smoking status for the present study was as follows: Never/light smokers ( $<20$ pack-years), or heavy smokers ( $\geq 20$ pack-years). Alcohol consumption status was assessed as the daily ethanol intake calculated as follows: One serving of sake contains $\sim 23 \mathrm{~g}$ ethanol, which is roughly the equivalent of two U.S. standard drinks, where one U.S. drink contains $14 \mathrm{~g}$ ethanol (7). The recommended daily maximum amount of alcohol was based on the report regarding the limitation on daily ethanol intake issued by the Ministry of Health, Labor and Welfare (20 g/day; Healthy Japan 21, a national healthcare movement). According to the prospective large cohort study showing the lowest all-cause mortality including cancer in both Japanese men and women with ethanol intake $<23 \mathrm{~g} /$ day (7), the subjects were classified as non/light drinkers ( $<23 \mathrm{~g} /$ day), or heavy drinkers $(<23 \mathrm{~g} /$ day $)$.

All patients and controls provided written informed consent to participate in the present study prior to the start of the study, and the Bioethics Committee of Okayama University Medical School (Okayama, Japan) approved the present study.

Genotype analysis. Genomic DNA was extracted from peripheral blood lymphocytes or freshly frozen non-neoplastic colorectal mucosae according to standard procedures using proteinase $\mathrm{K}$ and phenol-chloroform (24). The genotyping of the polymorphisms including NINEIN Pro1111Ala (rs2236316) was performed using SNaPshot kit (Applied Biosystems; Thermo Fisher Scientific, Inc.) according to the manufacture's instruction. Briefly, the target region for genotyping was amplified by PCR, with a final reaction volume of $10 \mu \mathrm{l}$ containing $10 \mathrm{ng}$ template DNA, 1.0 pmol of each primer, $2.0 \mathrm{mM}$ dNTPs, $1 \mu 1$ 10x PCR buffer and 0.25 units Taq DNA polymerase (Takara Bio, Inc.). The thermocycling conditions were: Initial denaturation at $94^{\circ} \mathrm{C}$ for $3 \mathrm{~min}$; followed by 32 cycles at $94^{\circ} \mathrm{C}$ for $30 \mathrm{sec}, 60^{\circ} \mathrm{C}$ for $30 \mathrm{sec}$ and $72^{\circ} \mathrm{C}$ for $30 \mathrm{sec}$; and a final extension step of $72^{\circ} \mathrm{C}$ for $7 \mathrm{~min}$. PCR products were treated with 2.0 units exonuclease I and 0.5 units shrimp alkaline phosphatase to remove unreacted primers and dNTPs by incubating at $37^{\circ} \mathrm{C}$ for $90 \mathrm{~min}$ and at $75^{\circ} \mathrm{C}$ for $15 \mathrm{~min}$. The first PCR primer set sequences were: Sense 5'-GGAAAATGT GAAAATGGCTACTGA-3' and anti-sense 5'-GACTCCTCT ATTTTGACTTCCTGT-3'.

Subsequently, a single nucleotide primer extension reaction was performed using SNaPshot kit with a final reaction volume of $10 \mu \mathrm{l}$, containing $3 \mu \mathrm{l}$ purified PCR products, $20 \mathrm{mM}\left(\mathrm{NH}_{4}\right)^{2} \mathrm{SO}_{4}$ and $2 \mu \mathrm{l}$ SNaPshot Ready Reaction mix containing fluorescently labeled ddNTPs and DNA polymerase. The sequence of the genotyping primer for NINEIN Pro1111Ala was 5'-TTTTTTTTTTTTTTTTTTTTTTTT TTGTTAGTAATGTCTTCTTGTTTGGATGAG-3'. The thermocycling conditions were: Initial denaturation at $96^{\circ} \mathrm{C}$ for $3 \mathrm{~min}$; followed by 30 cycles at $96^{\circ} \mathrm{C}$ for $10 \mathrm{sec}, 50^{\circ} \mathrm{C}$ for $5 \mathrm{sec}$ and $60^{\circ} \mathrm{C}$ for $30 \mathrm{sec}$. To remove unincorporated ddNTPs, the reaction was incubated with 1.0 unit shrimp alkaline phosphatase at $37^{\circ} \mathrm{C}$ for $90 \mathrm{~min}$ and at $75^{\circ} \mathrm{C}$ for $15 \mathrm{~min}$ and then $8.5 \mu \mathrm{l}$ HI-Di formamide, $0.5 \mu \mathrm{l}$ Genescan 
120 LIZ size standard (Applied Biosystems; Thermo Fisher Scientific, Inc.) and $1 \mu 1$ reaction mixture were combined and denatured at $95^{\circ} \mathrm{C}$ for $5 \mathrm{~min}$ and incubated at $4{ }^{\circ} \mathrm{C}$ for $2 \mathrm{~min}$. The products were electrophoresed using an ABI PRISM 3100 Genetic Analyzer (Applied Biosystems; Thermo Fisher Scientific, Inc.) and analyzed using GeneMapper version 3.0 Software SNaPshot Analysis (Applied Biosystems; Thermo Fisher Scientific, Inc.).

Human genetic variation database (HGVD) is a publicly available database of known genetic variations in 1,208 Japanese individuals, and was used as an additional representative of healthy controls to confirm the validity of genotype distributions in the control group (25). According to databases instructions, the genotype count of objective the single nucleotide polymorphism, rs2236316 was obtained.

Human Protein Atlas Database analysis. Protein expression of NINEIN in colorectal cancer patient tissues and its correlation with prognosis was examined by using Human Protein Atlas Database (proteinatlas.org/).

Statistical analysis. All analyses were performed using SPSS version 24 (IBM Corp.). Allele frequency was calculated by direct counting. Deviation of the genotype frequency from the Hardy-Weinberg equilibrium was analyzed using Pearson's $\chi^{2}$ test. The distribution of genotype frequencies between cancer cases and controls were analyzed using a $\chi^{2}$ test. The risk of CRC was estimated using odds ratio (ORs) and 95\% confidence interval (CIs). Analyses were adjusted for sex, age, smoking status and alcohol consumption status using a multivariate logistic regression model by comparing the genotypes between the cases and controls. $\mathrm{P}<0.05$ was considered to indicate a statistically significant difference.

\section{Results}

Association of the NINEIN Proll11Ala polymorphism with CRC risk. The demographics and clinicopathological characteristics of the patients with CRC and controls are presented in Table I. There was no difference in sex distribution between the patients with CRC and controls, whereas patients with CRC had a higher median age, consumed more alcohol and smoked more. Genotype analysis of NINEIN Pro1111Ala polymorphism (rs2236316) in the patients with CRC and controls are summarized in Table II. The Ala/Ala genotype was significantly associated with the risk of CRC compared with the Pro/Pro genotype $(\mathrm{OR}=2.09,95 \% \mathrm{CI}$ 1.12-3.91, $\mathrm{P}=0.02)$, whereas allele frequency differences [Pro-allele/Ala-allele: 307/93 (76.8\%/23.3\%) for cases and $1815 / 467$ (79.5\%/20.5\%) for controls] were not associated with a risk of $\mathrm{CRC}(\mathrm{P}=0.21)$.

Among males, the Ala/Ala genotype was more significantly associated with an increased risk of CRC in the recessive genetic model compared with the Pro/Pro and Pro/Ala genotypes $(\mathrm{OR}=2.76,95 \% \mathrm{CI} 1.27-6.04, \mathrm{P}=0.01)$. There was no association between the genotypes and the risk of $\mathrm{CRC}$ among females (Table III).

The genotype frequency of rs2236316 in the control group was in Hardy-Weinberg equilibrium, both in the entire cohort, and in the patients obtained from each institution (data not
Table I. Characteristics of patients with CRC and the healthy controls.

\begin{tabular}{lccc}
\hline Characteristics & $\begin{array}{c}\text { CRC } \\
\text { patients, n (\%) }\end{array}$ & $\begin{array}{c}\text { Controls, } \\
\mathrm{n}(\%)\end{array}$ & P-value \\
\hline Total & $200(100)$ & $1,141(100)$ & 0.66 \\
Males & $115(57.5)$ & $675(59.2)$ & \\
Females & $85(42.5)$ & $466(40.8)$ & \\
Age, years & & & $<0.001^{\text {b }}$ \\
$<50$ & $18(9)$ & $255(22.3)$ & \\
$50-59$ & $57(28.5)$ & $501(43.9)$ & \\
$60-69$ & $58(29)$ & $261(22.9)$ & \\
$\geq 70$ & $67(33.5)$ & $124(10.9)$ & \\
Median & 64 & 55 & \\
Range & $23-89$ & $32-94$ & \\
Smoking & & & $0.01^{\text {a }}$ \\
Never/light smokers & $119(59.5)$ & $782(68.5)$ & \\
Heavy smokers & $81(40.5)$ & $359(31.5)$ & \\
Alcohol consumption & & \multicolumn{2}{c}{$<0.001^{\text {b }}$} \\
Never/light drinkers & $137(68.5)$ & $906(79.4)$ & \\
Heavy drinkers & $63(31.5)$ & $235(20.6)$ & \\
\hline
\end{tabular}

${ }^{\mathrm{a}} \mathrm{P}<0.05,{ }^{\mathrm{b}} \mathrm{P}<0.001$. CRC, colorectal cancer.

shown). The genotype frequency of rs2236316 in the control group was similar to that of HGVD, which consisted of 1,208 Japanese individuals, suggesting that the sample used in the present study was representative of the general Japanese population (25). In HGVD, the rs2236316 genotype distribution was 748 (62\%), 412 (34\%) and 43 (4\%) for Pro/Pro, Pro/Ala and Ala/Ala, respectively.

Association of the NINEIN genotype with smoking and alcohol consumption. Subsequently, the association between smoking or alcohol consumption, NINEIN Pro1111Ala genotypes and the risk of CRC were assessed in the stratified analyses (Table IV). Among the never/light drinkers ( $<23 \mathrm{~g}$ of ethanol/day), there was a significant association of the Ala/Ala genotype with an increased risk of CRC compared with the Pro/Pro and Pro/Ala genotype in the recessive genetic model $(\mathrm{OR}=2.59,95 \%$ CI 1.31-5.12, $\mathrm{P}=0.006)$. There was no significant association among smokers in the stratified analysis. As the Ala/Ala genotype showed a significantly increased risk of CRC only in males, a stratified analysis of smoking and alcohol consumption among males was performed. The results are summarized in Table V. Only the group of the never/light drinkers with the Ala/Ala genotype exhibited a significant association with CRC risk in the recessive model compared with the Pro/Pro and Pro/Ala genotypes ( $\mathrm{OR}=4.90,95 \%$ CI $1.91-12.58, \mathrm{P}=0.001)$.

Association of the NINEIN genotype with cancer locations. The association between the NINEIN genotypes and cancer locations among male patients were analyzed, as the left and right colon have different embryologic origins, and are thus subject to different epigenetic backgrounds $(8,10)$. Separately 
Table II. Association between NINEIN Pro1111Ala (rs2236316) genotype and risk of CRC.

\begin{tabular}{lccc}
\hline Genotype & CRC patients, $n(\%)$ & Controls, $n(\%)$ & Adjusted OR $(95 \% \text { CI })^{\mathrm{b}}(\mathrm{P}-\mathrm{value}$ \\
\hline Total & $200(100)$ & $1,141(100)$ & \\
Pro/Pro $^{\mathrm{c}}$ & $124(62)$ & $720(63.1)$ & $0.99(0.70-1.39)$ \\
Pro/Ala & $59(29.5)$ & $375(32.9)$ & $2.09(1.12-3.91)$ \\
Ala/Ala & $17(8.5)$ & $46(4)$ & $1.11(0.81-1.54)$ \\
Pro/Ala+Ala/Ala & $76(38)$ & $421(36.9)$ & 0.94 \\
Pro/Pro+Pro/Ala & $183(91.5)$ & $1,095(96)$ & $2.1(1.14-3.89)$ \\
Ala/Ala & $17(8.5)$ & $46(4)$ & 0.51 \\
\hline
\end{tabular}

${ }^{\mathrm{a}} \mathrm{P}<0.05$. ${ }^{\mathrm{b}}$ Adjusted for sex, age, smoking, and alcohol consumption. ${ }^{\mathrm{c}}$ Used as reference. $\mathrm{CRC}$, colorectal cancer.

Table III. Association between NINEIN genotype and sex in patients with CRC.

A, Males

\begin{tabular}{lccc}
\hline Genotype & CRC patients, n $(\%)$ & Controls, n $(\%)$ & Adjusted OR $(95 \% \text { CI })^{\mathrm{b}}$ P-value \\
\hline Total & $115(100)$ & $675(100)$ & \\
Pro/Pro $^{c}$ & $74(64.3)$ & $422(62.5)$ & $0.85(0.53-1.36)$ \\
Pro/Ala & $30(26.1)$ & $228(33.8)$ & $2.63(1.19-5.81)$ \\
Ala/Ala & $11(9.6)$ & $25(3.7)$ & $1.04(0.67-1.59)$ \\
Pro/Ala+Ala/Ala & $41(35.7)$ & $253(37.5)$ & 0.5 \\
Pro/Pro+Pro/Ala & $104(90.4)$ & $650(96.3)$ & $2.76(1.27-6.04)$ \\
Ala/Ala & $11(9.6)$ & $25(3.7)$ & 0.87 \\
\hline
\end{tabular}

B, Females

\begin{tabular}{lccc}
\hline Genotype & CRC patients, n $(\%)$ & Controls, n $(\%)$ & Adjusted OR $(95 \% \text { CI })^{\mathrm{b}}$ P-value \\
\hline Total & $85(100)$ & $466(100)$ & \\
Pro/Pro $^{c}$ & $50(58.8)$ & $298(63.9)$ & $1.21(0.72-2.04)$ \\
Pro/Ala & $29(34.1)$ & $147(31.5)$ & $1.5(0.54-4.17)$ \\
Ala/Ala & $6(7.1)$ & $21(4.5)$ & $1.25(0.76-2.05)$ \\
Pro/Ala+Ala/Ala & $35(41.2)$ & $168(36.1)$ & 0.47 \\
Pro/Pro+Pro/Ala & $79(92.9)$ & $21(4.5)$ & $1.4(0.51-3.84)$ \\
Ala/Ala & $6(7.1)$ & $21(95.5)$ & 0.37 \\
\hline
\end{tabular}

${ }^{\mathrm{a}} \mathrm{P}<0.05 .{ }^{\mathrm{b}}$ Adjusted for sex, age, smoking, and alcohol consumption. ${ }^{\mathrm{c}}$ Used as reference. CRC, colorectal cancer.

analyzing the left side of the colon (the descending colon, the sigmoid colon and the rectum), and the right side of the colon (the cecum, the ascending colon and the transverse colon), only the left colon-group exhibited increased risk if they had an Ala/Ala genotype compared with the Pro/Pro and Pro/Ala genotypes in the recessive model $(\mathrm{OR}=2.42,95 \%$ CI 1.01-5.82, $\mathrm{P}=0.049$; Table VI). Further comparisons between colon cancer and rectal cancer (left-sided) patients, showed that only rectal cancer cases indicated a significant association with an Ala/Ala genotype $(\mathrm{OR}=3.30,95 \% \mathrm{CI} 1.26-8.61, \mathrm{P}=0.01)$, whereas such an association was not observed in cancer of any other regions (Table VI), nor in the total patients and female patients (data not shown).
Stratification of the association of the NINEIN genotype with a combination of smoking or alcohol consumption status and the location of CRC in males. The stratified analysis of the combined effects of cancer locations and smoking or alcohol consumption history among males are shown in Table VII. In this table analyses without significant adjusted odds ratio (aOR) were omitted. For smoking, male heavy smokers showed an aOR of $6.94(\mathrm{P}=0.03)$ with right colon cancer, and male light smokers showed an aOR of $8.83(\mathrm{P}=0.01)$ among rectal cancer. However, the range of their CIs were notably wide in both cases, 1.18-40.82 for the former and 1.92-40.56 for the latter, suggesting a comparably low reliability. For alcohol consumption, showing multiple significant ORs in the stratified light 
Table IV. Association between NINEIN genotype and smoking or alcohol consumption in patients with CRC.

A, Never/light smokers

\begin{tabular}{|c|c|c|c|c|}
\hline Genotype & CRC patients, n (\%) & Controls, n $(\%)$ & Adjusted $\mathrm{OR}^{\mathrm{b}}(95 \% \mathrm{CI})$ & $\mathrm{P}$-value \\
\hline Total & $119(100)$ & $782(100)$ & & \\
\hline Pro/Pro ${ }^{c}$ & $71(59.7)$ & $492(62.9)$ & & \\
\hline Pro/Ala & $38(31.9)$ & $257(32.9)$ & $1.04(0.67-1.6)$ & 0.86 \\
\hline Ala/Ala & $10(8.4)$ & $33(4.2)$ & $1.97(0.89-4.33)$ & 0.09 \\
\hline Pro/Ala+Ala/Ala & $48(40.3)$ & $290(37.1)$ & $1.15(0.77-1.72)$ & 0.5 \\
\hline Pro/Pro+Pro/Ala ${ }^{c}$ & $109(91.6)$ & $749(95.8)$ & & \\
\hline Ala/Ala & $10(8.4)$ & $33(4.2)$ & $1.94(0.89-4.21)$ & 0.09 \\
\hline
\end{tabular}

B, Heavy smokers

\begin{tabular}{lccc}
\hline Genotype & CRC patients, n $(\%)$ & Controls, n (\%) & Adjusted OR $(95 \%$ CI $)$ \\
\hline Total & $81(100)$ & $359(100)$ & \\
Pro/Pro $^{\mathrm{c}}$ & $53(65.4)$ & $228(63.5)$ & \\
Pro/Ala & $21(25.9)$ & $118(32.9)$ & $0.99(0.55-1.78)$ \\
Ala/Ala & $7(8.6)$ & $13(3.6)$ & $2.38(0.84-6.71)$ \\
Pro/Ala+Ala/Ala & $28(34.6)$ & $131(36.5)$ & $1.16(0.67-1.98)$ \\
Pro/Pro+Pro/Ala & $74(91.4)$ & $346(96.4)$ & 0.97 \\
Ala/Ala & $7(8.6)$ & $13(3.6)$ & $2.39(0.86-6.63)$ \\
\hline
\end{tabular}

C, Never/light drinkers

\begin{tabular}{lccc}
\hline Genotype & CRC patients, $n(\%)$ & Controls, $n(\%)$ & Adjusted OR $(95 \% \text { CI })^{\mathrm{b}}(\mathrm{P}-\mathrm{value}$ \\
\hline Total & $137(100)$ & $906(100)$ & \\
Pro/Pro $^{\mathrm{c}}$ & $80(58.4)$ & $572(63.1)$ & \\
Pro/Ala & $43(31.4)$ & $298(32.9)$ & $1.08(0.72-1.62)$ \\
Ala/Ala & $14(10.2)$ & $36(4)$ & $2.65(1.32-5.33)$ \\
Pro/Ala+Ala/Ala & $57(41.6)$ & $334(36.9)$ & $1.26(0.86-1.83)$ \\
Pro/Pro+Pro/Ala & $123(89.8)$ & $870(96)$ & $2.59(1.31-5.12)$ \\
Ala/Ala & $14(10.2)$ & $36(4)$ & $0.01^{\mathrm{a}}$ \\
\hline
\end{tabular}

D, Heavy drinkers

\begin{tabular}{lccc}
\hline Genotype & CRC patients, $\mathrm{n}(\%)$ & Controls, $\mathrm{n}(\%)$ & Adjusted OR $^{\mathrm{b}}(95 \% \mathrm{CI})$ \\
\hline Total & $63(100)$ & $235(100)$ & \\
Pro/Pro $^{\mathrm{c}}$ & $44(69.8)$ & $148(63)$ & \\
Pro/Ala & $16(25.4)$ & $77(32.8)$ & $0.84(0.43-1.64)$ \\
Ala/Ala & $3(4.8)$ & $10(4.3)$ & $1.00(0.24-4.08)$ \\
Pro/Ala+Ala/Ala & $19(30.2)$ & $87(37)$ & $0.86(0.46-1.62)$ \\
Pro/Pro+Pro/Ala & $225(95.7)$ & $1.05(0.26-4.25)$ \\
Ala/Ala & $60(95.2)$ & $10(4.3)$ & 0.61
\end{tabular}

${ }^{\mathrm{a}} \mathrm{P}<0.05$. ${ }^{\mathrm{b}}$ Adjusted for sex, age, smoking, and alcohol consumption. ${ }^{\mathrm{c}}$ Used as reference. CRC, colorectal cancer.

drinkers, the effects of light drinking on the risk of the Ala/Ala genotype are presented above. Overall, light drinkers showed an aOR of $2.65(\mathrm{P}=0.01)$, higher than that of the non-stratified overall aOR of $2.09(\mathrm{P}=0.02$; Table IV). Male-only light drinkers showed an aOR of $4.83(\mathrm{P}=0.001)$ (Table V); 9.51 $(\mathrm{P}=0.003)$ for right colon cancer; and $3.73(\mathrm{P}=0.02)$ for left colon cancer (Table VII). Male light drinkers were further stratified into rectal cancer and colon (other than rectal) cancer, 
Table V. Association between NINEIN genotype and smoking or alcohol consumption in male patients with CRC.

A, Never/light smokers

\begin{tabular}{lccc}
\hline Genotype & CRC patients, $(\%)$ & Controls, n $(\%)$ & Adjusted OR $(95 \% \text { CI })^{\mathrm{P}}(\mathrm{P}-\mathrm{value}$ \\
\hline Total & $39(100)$ & $336(100)$ & \\
Pro/Pro $^{\mathrm{c}}$ & $24(61.5)$ & $207(61.6)$ & $0.8(0.38-1.69)$ \\
Pro/Ala & $11(28.2)$ & $117(34.8)$ & $2.99(0.88-10.14)$ \\
Ala/Ala & $4(10.3)$ & $12(3.6)$ & $0.99(0.50-1.97)$ \\
Pro/Ala+Ala/Ala & $15(38.5)$ & $129(38.4)$ & 0.56 \\
Pro/Pro+Pro/Ala & $35(89.7)$ & $324(96.4)$ & $3.23(0.98-10.69)$ \\
Ala/Ala & $4(10.3)$ & $12(3.6)$ & 0.98 \\
\hline
\end{tabular}

B, Heavy smokers

\begin{tabular}{lccc}
\hline Genotype & CRC patients, $n(\%)$ & Controls, $n(\%)$ & Adjusted OR $(95 \% \text { CI })^{\mathrm{P}-\mathrm{value}}$ \\
\hline Total & $76(100)$ & $339(100)$ & \\
Pro/Pro $^{\mathrm{c}}$ & $50(65.8)$ & $215(63.4)$ & $0.99(0.54-1.83)$ \\
Pro/Ala & $19(25)$ & $111(32.7)$ & $2.39(0.84-6.80)$ \\
Ala/Ala & $7(9.2)$ & $13(3.8)$ & $1.17(0.67-2.06)$ \\
Pro/Ala+Ala/Ala & $26(34.2)$ & $124(36.6)$ & 0.98 \\
Pro/Pro+Pro/Ala & $69(90.8)$ & $326(96.2)$ & $2.4(0.86-6.71)$ \\
Ala/Ala & $7(9.2)$ & $13(3.8)$ & 0.58 \\
\hline
\end{tabular}

C, Never/light drinkers

\begin{tabular}{lccc}
\hline Genotype & CRC patients, n $(\%)$ & Controls, n $(\%)$ & Adjusted OR $(95 \%$ CI $)$ \\
\hline Total & $57(100)$ & $456(100)$ & \\
Pro/Pro $^{c}$ & $33(57.9)$ & $286(62.7)$ & \\
Pro/Ala & $16(28.1)$ & $155(34)$ & $0.96(0.50-1.81)$ \\
Ala/Ala & $8(14)$ & $15(3.3)$ & $4.83(1.84-12.69)$ \\
Pro/Ala+Ala/Ala & $24(42.1)$ & $170(37.3)$ & $1.3(0.74-2.31)$ \\
Pro/Pro+Pro/Ala & $441(96.7)$ & 0.89 \\
Ala/Ala & $89(86)$ & $15(3.3)$ & $4.9(1.91-12.58)$ \\
\hline
\end{tabular}

$\mathrm{D}$, Heavy drinkers

\begin{tabular}{|c|c|c|c|c|}
\hline Genotype & CRC patients, n (\%) & Controls, n (\%) & Adjusted OR ${ }^{b}(95 \%$ CI) & P-value \\
\hline Total & $58(100)$ & $219(100)$ & & \\
\hline Pro/Pro ${ }^{c}$ & $41(70.7)$ & $136(62.1)$ & & \\
\hline Pro/Ala & $14(24.1)$ & $73(33.3)$ & $0.78(0.39-1.57)$ & 0.48 \\
\hline Ala/Ala & $3(5.2)$ & $10(4.6)$ & $0.97(0.24-3.94)$ & 0.96 \\
\hline Pro/Ala+Ala/Ala & $17(29.3)$ & $83(37.9)$ & $0.81(0.42-1.56)$ & 0.52 \\
\hline Pro/Pro+Pro/Ala ${ }^{c}$ & $55(94.8)$ & $209(95.4)$ & & \\
\hline Ala/Ala & $3(5.2)$ & $10(4.6)$ & $1.04(0.26-4.19)$ & 0.96 \\
\hline
\end{tabular}

${ }^{\mathrm{a}} \mathrm{P}<0.01 .{ }^{\mathrm{b}}$ Adjusted for sex, age, smoking, and alcohol consumption. ${ }^{\mathrm{c}}$ Used as reference. CRC, colorectal cancer.

and a significant aOR was observed only in male patients with rectal cancer; the colon (other than rectal) cancer also showed an almost significant result ( $\mathrm{aOR}=3.92, \mathrm{P}=0.0501$; Table VII).
Association of the NINEIN protein expression with CRC prognosis. Alteration of NINEIN at the genomic and transcriptional levels remains to be investigated in the CRC. The Human Protein 
Table VI. Association between NINEIN genotype and location of CRC in males.

A, Right colon cancer

\begin{tabular}{lccc}
\hline Genotype & CRC patients, $n(\%)$ & Controls, $n(\%)$ & Adjusted OR $(95 \% \text { CI })^{\mathrm{b}}(\mathrm{P}-\mathrm{value}$ \\
\hline Total & $24(100)$ & $675(100)$ & \\
Pro/Pro $^{\mathrm{c}}$ & $14(58.3)$ & $422(62.5)$ & $0.97(0.38-2.47)$ \\
Pro/Ala & $7(29.2)$ & $228(33.8)$ & $3.6(0.95-13.73)$ \\
Ala/Ala & $3(12.5)$ & $25(3.7)$ & $1.25(0.54-2.88)$ \\
Pro/Ala+Ala/Ala & $10(41.7)$ & $253(37.5)$ & 0.95 \\
Pro/Pro+Pro/Ala & $21(87.5)$ & $650(96.3)$ & $3.64(0.99-13.37)$ \\
Ala/Ala & $3(12.5)$ & $25(3.7)$ & 0.6 \\
\hline
\end{tabular}

B, Left colon cancer

\begin{tabular}{lccc}
\hline Genotype & CRC patients, n $(\%)$ & Controls, $n(\%)$ & Adjusted OR $(95 \% \text { CI })^{\mathrm{b}}(\mathrm{P}-\mathrm{value}$ \\
\hline Total & $89(100)$ & $675(100)$ & \\
Pro/Pro $^{\mathrm{c}}$ & $58(65.2)$ & $422(62.5)$ & $0.84(0.49-1.41)$ \\
Pro/Ala & $23(25.8)$ & $228(33.8)$ & $2.29(0.94-5.57)$ \\
Ala/Ala & $8(9)$ & $25(3.7)$ & $1(0.62-1.61)$ \\
Pro/Ala+Ala/Ala & $31(34.8)$ & $253(37.5)$ & 0.5 \\
Pro/Pro+Pro/Ala & $81(91)$ & $650(96.3)$ & $2.42(1.015 .82)$ \\
Ala/Ala & $8(9)$ & $25(3.7)$ & 0.07 \\
\hline
\end{tabular}

C, Colon cancer (other than rectal cancer)

\begin{tabular}{lccc}
\hline Genotype & CRC patients, n $(\%)$ & Controls, $n(\%)$ & Adjusted OR $(95 \%$ CI $)$ \\
\hline Total & $52(100)$ & $675(100)$ & \\
Pro/Pro $^{c}$ & $37(71.2)$ & $422(62.5)$ & \\
Pro/Ala & $11(21.2)$ & $228(33.8)$ & $0.63(0.31-1.28)$ \\
Ala/Ala & $4(7.7)$ & $25(3.7)$ & $1.8(0.57-5.71)$ \\
Pro/Ala+Ala/Ala & $15(28.8)$ & $253(37.5)$ & $0.76(0.40-1.44)$ \\
Pro/Pro+Pro/Ala & $650(96.3)$ & 0.2 \\
Ala/Ala & $48(92.3)$ & $25(3.7)$ & $2.05(0.65-6.43)$ \\
\hline
\end{tabular}

D, Rectal cancer

\begin{tabular}{lccc}
\hline Genotype & CRC patients, $\mathrm{n}(\%)$ & Controls, $\mathrm{n}(\%)$ & Adjusted OR $^{\mathrm{b}}(95 \% \mathrm{CI})$ \\
\hline Total & $61(100)$ & $675(100)$ & \\
Pro/Pro & & \\
Pro/Ala & $35(57.4)$ & $422(62.5)$ & $1.15(0.63-2.08)$ \\
Ala/Ala & $19(31.1)$ & $228(33.8)$ & $3.3(1.26-8.61)$ \\
Pro/Ala+Ala/Ala & $7(11.5)$ & $25(3.7)$ & $1.39(0.80-2.40)$ \\
Pro/Pro+Pro/Ala & $253(37.5)$ & 0.66 \\
Ala/Ala & $26(42.6)$ & $650(96.3)$ & $3.15(1.24-8.02)$
\end{tabular}

${ }^{\mathrm{a}} \mathrm{P}<0.01 .{ }^{\mathrm{b}}$ Adjusted for sex, age, smoking, and alcohol consumption. ${ }^{\mathrm{c}}$ Used as reference. CRC, colorectal cancer.

Atlas is a powerful public database integrating various omics data on human proteins in cells, tissues and organs, and can predict the association of level of particular protein interested with survival of patients with wide spectrum of cancer. Data analysis on the immunohistochemical study of the NINEIN proteins in CRC patients showed that patients with upregulated expression (as determined by the intensity of expression) strongly were associated with a poor prognosis $(\mathrm{P}=0.035, \mathrm{n}=597)$. 
Table VII. Association between NINEIN genotype and combination of smoking, alcohol consumption and location of CRC in males.

A, Right colon cancer

\begin{tabular}{|c|c|c|c|c|}
\hline Genotype & CRC patients, n (\%) & Controls, n (\%) & Adjusted OR ${ }^{\mathrm{c}}(95 \% \mathrm{CI})$ & P-value \\
\hline \multicolumn{5}{|l|}{ Heavy smoker } \\
\hline Total & $11(100)$ & $339(100)$ & & \\
\hline Pro/Pro ${ }^{d}$ & $5(45.4)$ & $215(63.4)$ & & \\
\hline Pro/Ala & $4(36.4)$ & $111(32.7)$ & $1.78(0.46-6.96)$ & 0.41 \\
\hline Ala/Ala & $2(18.2)$ & $13(3.8)$ & $6.94(1.18-40.82)$ & $0.03^{\mathrm{a}}$ \\
\hline Pro/Ala+Ala/Ala & $6(54.5)$ & $124(36.6)$ & $2.39(0.69-8.21)$ & 0.17 \\
\hline Pro/Pro+Pro/Ala ${ }^{\mathrm{d}}$ & $9(81.8)$ & $326(96.2)$ & & \\
\hline Ala/Ala & $2(2)$ & $13(3.8)$ & $5.57(1.06-29.44)$ & $0.04^{\mathrm{a}}$ \\
\hline \multicolumn{5}{|l|}{ Never/light drinkers } \\
\hline Total & $15(100)$ & $456(100)$ & & \\
\hline Pro/Pro ${ }^{d}$ & $7(46.7)$ & $286(62.7)$ & & \\
\hline Pro/Ala & $5(33.3)$ & $155(34)$ & $1.43(0.44-4.65)$ & 0.55 \\
\hline Ala/Ala & $3(20)$ & $15(3.3)$ & $9.51(2.13-42.49)$ & $0.003^{\mathrm{b}}$ \\
\hline Pro/Ala+Ala/Ala & $8(53.3)$ & $170(37.3)$ & $2.1(0.74-5.97)$ & 0.17 \\
\hline Pro/Pro+Pro/Ala ${ }^{\mathrm{d}}$ & $12(80)$ & $441(96.7)$ & & \\
\hline Ala/Ala & $3(20)$ & $15(3.3)$ & $8.28(2.02-33.91)$ & $0.003^{\mathrm{b}}$ \\
\hline
\end{tabular}

B, Left colon cancer

\begin{tabular}{lccc}
\hline Genotype & CRC patients, $n(\%)$ & Controls, $n(\%)$ & Adjusted OR $(95 \%$ CI $)$ \\
\hline Never/light drinkers & $42(100)$ & $456(100)$ & \\
Total & $26(61.9)$ & $286(62.7)$ & \\
Pro/Pro ${ }^{\mathrm{d}}$ & $11(26.2)$ & $155(34)$ & $0.83(0.40-1.74)$ \\
Pro/Ala & $5(11.9)$ & $15(3.3)$ & $3.73(1.21-11.52)$ \\
Ala/Ala & $16(38.1)$ & $170(37.3)$ & $1.09(0.5-2.12)$ \\
Pro/Ala+Ala/Ala & $37(88.1)$ & $441(96.7)$ & 0.62 \\
Pro/Pro+Pro/Ala & $15(3.3)$ & $3.97(1.31-11.96)$ \\
Ala/Ala & $5(11.9)$ & 0.79 & $0.01^{\mathrm{a}}$ \\
\hline
\end{tabular}

C, Colon cancer (other than rectal cancer)

\begin{tabular}{lccc}
\hline Genotype & CRC patients, $\mathrm{n}(\%)$ & Controls, $\mathrm{n}(\%)$ & Adjusted OR $^{\mathrm{c}}(95 \% \mathrm{CI})$ \\
\hline Never/light drinkers & $25(100)$ & & \\
Total & $16(64)$ & $256(100)$ & \\
Pro/Pro & & & \\
Pro/Ala & $6(24)$ & $155(62.7)$ & $0.74(0.28-1.94)$ \\
Ala/Ala & $3(12)$ & $15(3.3)$ & $3.92(0.999-15.38)$ \\
Pro/Ala+Ala/Ala & $9(36)$ & $170(37.3)$ & $1.01(0.43-2.36)$ \\
Pro/Pro+Pro/Ala & & & \\
Ala/Ala & $22(88)$ & $15(3.3)$ & $4.31(1.13-16.46)$ \\
\hline
\end{tabular}

D, Rectal cancer

\begin{tabular}{llll}
\hline Genotype & CRC patients, $n(\%)$ & Controls, n (\%) & Adjusted OR $(95 \%$ CI) \\
\hline
\end{tabular}

Heavy smoker

$\begin{array}{lrl}\text { Total } & 17(100) & 336(100) \\ \text { Pro/Pro } & 6(35.3) & 207(61.6)\end{array}$


Table VII. Continued.

D, Rectal cancer

\begin{tabular}{|c|c|c|c|c|}
\hline Genotype & CRC patients, n (\%) & Controls, n (\%) & Adjusted OR $(95 \%$ CI) & P-value \\
\hline Pro/Ala & $8(47.1)$ & $117(34.8)$ & $2.28(0.77-6.77)$ & 0.14 \\
\hline Ala/Ala & $3(17.6)$ & $12(3.6)$ & $8.83(1.92-40.56)$ & $0.01^{\mathrm{a}}$ \\
\hline Pro/Ala+Ala/Ala & $11(64.7)$ & $129(38.4)$ & $2.86(1.03-7.96)$ & $0.04^{\mathrm{a}}$ \\
\hline $\mathrm{Pro} / \mathrm{Pro}+\mathrm{Pro} / \mathrm{Ala}^{\mathrm{d}}$ & $14(82.4)$ & $324(96.4)$ & & \\
\hline Ala/Ala & $3(17.6)$ & $12(3.6)$ & $6.01(1.48-24.33)$ & $0.01^{\mathrm{a}}$ \\
\hline Genotype & CRC patients, n (\%) & Controls, n (\%) & Adjusted OR OR $^{\mathrm{c}}(95 \% \mathrm{CI})$ & P-value \\
\hline \multicolumn{5}{|l|}{ Never/light drinkers } \\
\hline Total & $30(100)$ & $456(100)$ & & \\
\hline Pro/Pro ${ }^{d}$ & $15(50)$ & $286(62.7)$ & & \\
\hline Pro/Ala & $10(33.3)$ & $155(34)$ & $1.4(0.6-3.26)$ & 0.44 \\
\hline Ala/Ala & $5(16.7)$ & $15(3.3)$ & $7.06(2.08-24.03)$ & $0.002^{\mathrm{b}}$ \\
\hline Pro/Ala+Ala/Ala & $15(50)$ & $170(37.3)$ & $1.9(0.88-4.09)$ & 0.1 \\
\hline Pro/Pro+Pro/Ala ${ }^{\mathrm{d}}$ & $25(83.3)$ & $441(96.7)$ & & \\
\hline Ala/Ala & $5(16.7)$ & $15(3.3)$ & $6.23(1.93-20.11)$ & $0.002^{\mathrm{b}}$ \\
\hline
\end{tabular}

${ }^{\mathrm{a}} \mathrm{P}<0.05,{ }^{\mathrm{b}} \mathrm{P}<0.01 .{ }^{\mathrm{c}}$ Adjusted for sex, age, smoking, and alcohol consumption. ${ }^{\mathrm{d}}$ Used as reference. CRC, colorectal cancer.

\section{Discussion}

In the present case-controlled study, the association between the NINEIN gene codon 1111 polymorphism and CRC risk in Japanese individuals was examined. NINEIN rs2236316 is a nonsynonymous single nucleotide polymorphism causing an amino acid substitution of Proline to Alanine at codon 1111. It was shown that the NINEIN Prol111Ala variant was associated with the occurrence of CRC in Japanese individuals, particularly in males and in tumors of the left colon. To the best of our knowledge, this is the first report demonstrating that a NINEIN rs2236316 polymorphism is associated with the risk of CRC. There are two studies from the Mayo Clinic reporting polymorphisms in the NINEIN gene associated with pancreatic cancer and breast cancer in Caucasian populations, focusing on mitosis regulation or centrosome structure and function pathways, respectively. In the pancreatic cancer study, NINEIN rs10145182 in intron 2 had a significant OR with a reduced risk, particularly in the never-smoker group (26). In contrast, in the breast cancer study, six single nucleotide polymorphisms of the NINEIN gene were identified, four of which were associated with an increased risk, and two of which were associated with a decreased risk of breast cancer, including rs10145182 (21). The rs2236316 polymorphism was not included in the breast cancer study.

Cigarette smoking and alcohol consumption have been suggested to influence the risk of CRC development in epidemiological studies (2-6). In a pooled meta-analysis based on cohort and case-control studies, smoking was not shown to significantly increase the risk of CRC in Japanese individuals (2), whereas, alcohol consumption was reported to have a more significant positive association with the risk of CRC in the Japanese than those in Western populations (7). In the present study, ORs were notably higher for the Ala/Ala genotype overall among the never/light drinkers in males, in both the stratified tumor locations (left and right), and in patients with rectal cancer. Considering there was no increased risk among heavy drinkers, it may be interpreted that NINEIN functions in a pathway independent of alcohol-associated oncogenesis.

The location of the tumor in patients with CRC has important clinical implications for the choice of therapy, as the left colon and the right colon have different embryonic origins, and they have different physiological and molecular backgrounds (8). Genomic instability of two major molecular mechanisms are respectively associated with CRC of the left and right colon; CIN is associated with tumors of the left colon and is a stage-independent poor prognostic factor, and MIN is primarily associated with tumors of the right colon and infrequent metastasis $(9,10)$. The Ala/Ala genotype was associated with an increased risk of CRC among patients with cancer of the left colon and rectal cancer in the stratified analysis of male patients with CRC. It has been estimated that chromosome instability in cancer cells is caused by aberrant expression and/or dysfunction of $~ 70$ genes involved in centrosome function and chromosome segregation, or dysregulation of their associated signaling pathways (11). Cyclin B1 and cyclin B2 serve essential roles in the fidelity of centrosome separation and chromosome segregation in $\mathrm{G} 2$ to $\mathrm{M}$ phase progression of the cell cycle, and are overexpressed in several types of human tumors, including CRC. Whereas elevated expression of cyclin $\mathrm{B} 1$ prevents a cohesion cleavage and sister chromatid segregation resulting in the generation of aneuploid cells, overexpression of cyclin B2 is involved in the centrosome pathway and initiates activation of Plk1 in an Aurora-A-dependent manner, resulting in a premature centrosome separation, spindle geometry defects and lagging 
chromosomes during mitosis (11). It may be worthwhile investigate whether NINEIN rs2236316 is associated with disease prognosis in patients with upregulated expression of NINEIN protein.

NINEIN localizes at a specific domain of the centrosome where it is essential for the recruitment of proteins associated with maturation of the daughter centrosome as well as for the reformation of specific aspects of the interphase centrosome architecture following mitosis (12). The NINEIN codon 1111 polymorphism is located within a large coiled-coil domain which is predicted to mediate the interaction with other centrosomal proteins (20). For instance, centrosomal protein CEP170 interacts with the domain containing amino acids 802-1,505 in NINEIN (27). Considering the importance of a cis-trans isomer of the proline residue in the protein structure, a proline to alanine substitution at rs2236316 may impact the protein-protein interaction of NINEIN, and as a result, centrosome structure and function and chromosome compression may be perturbed, resulting in genomic instability, a hallmark of cancer (28). Therefore, in the present study, the effect of an NINEIN P1111A substitution on centrosome localization and binding to CEP170 was assessed, but neither had any effect (data not shown). In future studies, the effects of amino acid substitutions in NINEIN by rs2236316 on centrosome function should be assessed to clarify the relationship with generation of CIN which is frequently observed in CRC.

The present case-controlled study has several limitations including a small sample size, some self-selection bias, such as volunteer bias, for the control group, and inadequate adjustment for various confounding factors, such as previous cancer treatment and drug disease-state interactions. For stratified analyses, small sample sizes may limit the statistical significance of the present study. A more detailed stratification of the present cases with a combined association of sex, lifestyle habit and the primary area of CRC could not be performed due to the small number of female heavy smokers/heavy drinkers. Nonetheless, an association between an NINEIN polymorphism and increased-risk groups of patients with CRC were determined.

In conclusion, it was shown that the variant allele Pro1111Ala of NINEIN was significantly associated with an increased risk of CRC among males, never/light drinkers and rectal cancer patients in males in Japan. Larger studies on the NINEIN polymorphisms are required to confirm the results of the present study, and the genotyping of NINEIN codon1111 may eventually enable the identification of individuals at a high risk for the development of CRC, providing these individuals with an incentive to improve their lifestyle choices.

\section{Acknowledgements}

The authors would like to thank Mrs Hiroko Hanafusa and Dr Norio Koide (Okayama University School of Medicine), Dr Yoshiro Kusaka (Kusaka Hospital), Dr Seiji Hamanishi and Dr Etsuo Senoh (Junpukai Health Maintenance Center) for their generous help in this study.

\section{Funding}

This work was supported by a Research start-up grant from Okayama University Graduate School of Medicine,
Grant-in-Aid from the Ministry of Education, Culture, Sports, Science and Technology (grant no. 12213084 and JP18K15752) and the Smoking Research Foundation.

\section{Availability of data and materials}

The datasets used and/or analyzed during the present study are available from the corresponding author on reasonable request.

\section{Authors' contribution}

AS, KSh and HK designed the study. YY, AS and HK drafted and revised the manuscript. SI and KSa assisted with data interpretation. HY and NM provided patient samples and clinicopathological data. YY, AS, SI, KSa, AI, YO, SK and YJ performed the experiments. All authors have read and approved the final manuscript.

\section{Ethics approval and consent to participate}

All patients and controls provided written informed consent prior to participation in the present study. The Bioethics Committee of Okayama University Medical School (Okayama, Japan) approved this study.

\section{Patient consent for publication}

Written consent for publication was obtained from all patients and controls involved in this study.

\section{Competing interests}

The authors declare that they have no competing interests.

\section{References}

1. The Editorial Board of the Cancer Statistics in Japan: Cancer statistics in Japan 16, 2017.

2. Mizoue T, Inoue M, Tanaka K, Tsuji I, Wakai K, Nagata C and Tsugane S; Research Group for the Development, Evaluation of Cancer Prevention Strategies in Japan: Tobacco smoking and colorectal cancer risk: An evaluation based on a systematic review of epidemiologic evidence among the Japanese population. Jpn J Clin Oncol 36: 25-39, 2006.

3. Inoue M, Sawada N, Matsuda T, Iwasaki M, Sasazuki S, Shimazu T, Shibuya K and Tsugane S: Attributable causes of cancer in Japan in 2005-systematic assessment to estimate current burden of cancer attributable to known preventable risk factors in Japan. Ann Oncol 23: 1362-1369, 2012.

4. Nagao M and Tsugane S: Cancer in Japan: Prevalence, prevention and the role of heterocyclic amines in human carcinogenesis. Genes Environ 38: 16, 2016.

5. Tamakoshi A, Nakamura K, Ukawa S, Okada E, Hirata M, Nagai A, Matsuda K, Kamatani Y, Muto K, Kiyohara Y, et al: Characteristics and prognosis of Japanese colorectal cancer patients: The BioBank Japan project. J Epidemiol 27 (3S): S36-S42, 2017.

6. Zaitsu M, Takeuchi T, Kobayashi Y and Kawachi I: Light to moderate amount of lifetime alcohol consumption and risk of cancer in Japan. Cancer 126: 1031-1040, 2020.

7. Lin Y, Kikuchi S, Tamakoshi A, Wakai K, Kawamura T, Iso H, Ogimoto I, Yagyu K, Obata Y and Ishibashi T; JACC Study Group: Alcohol consumption and mortality among middle-aged and elderly Japanese men and women. Ann Epidemiol 15: 590-597, 2005.

8. Baran B, Mert Ozupek N, Yerli Tetik N, Acar E, Bekcioglu O and Baskin Y: Difference between left-sided and right-sided colorectal cancer: A focused review of literature. Gastroenterol Res 11: 264-273, 2018. 
9. Gervaz P, Bucher P and Morel P: Two colons-two cancers: Paradigm shift and clinical implications. J Surg Oncol 88: 261-266, 2004.

10. Matsubara N: Epigenetic regulation and colorectal cancer. Dis Colon Rectum 55: 96-104, 2012.

11. de Cárcer $\mathrm{G}$ and Malumbres M: A centrosomal route for cancer genome instability. Nat Cell Biol 16: 504-506, 2014.

12. Ou YY, Mack GJ, Zhang M and Rattner JB: CEP110 and ninein are located in a specific domain of the centrosome associated with centrosome maturation. J Cell Sci 115: 1825-1835, 2002

13. Chen CH, Howng SL, Cheng TS, Chou MH, Huang CY and Hong YR: Molecular characterization of human ninein protein: Two distinct subdomains required for centrosomal targeting and regulating signals in cell cycle. Biochem Biophys Res Commun 308: 975-983, 2003.

14. Hong YR, Chen CH, Chuo MH, Liou SY and Howng SL: Genomic organization and molecular characterization of the human ninein gene. Biochem Biophys Res Commun 279: 989-995, 2000.

15. Kowanda M, Bergalet J, Wieczorek M, Brouhard G, Lécuyer É and Lasko P: Loss of function of the Drosophila Ninein-related centrosomal protein Bsg25D causes mitotic defects and impairs embryonic development. Biol Open 5: 1040-1051, 2016.

16. Goldspink DA, Rookyard C, Tyrrell BJ, Gadsby J, Perkins J, Lund EK, Galjart N, Thomas P, Wileman T and Mogensen MM: Ninein is essential for apico-basal microtubule formation and CLIP-170 facilitates its redeployment to non-centrosomal microtubule organizing centres. Open Biol 7: pii: 160274, 2017.

17. Hong YR, Chen CH, Chang JH, Wang S, Sy WD, Chou CK and Howng SL: Cloning and characterization of a novel human ninein protein that interacts with the glycogen synthase kinase 3beta. Biochim Biophys Acta 1492: 513-516, 2000.

18. Dauber A, Lafranchi SH, Maliga Z, Lui JC, Moon JE, McDeed C, Henke K, Zonana J, Kingman GA, Pers TH, et al: Novel microcephalic primordial dwarfism disorder associated with variants in the centrosomal protein ninein. J Clin Endocrinol Metab 97: E2140-E2151, 2012.

19. Zheng Y, Mennella V, Marks S, Wildonger J, Elnagdi E, Agard D and Megraw TL: The Seckel syndrome and centrosomal protein Ninein localizes asymmetrically to stem cell centrosomes but is not required for normal development, behavior, or DNA damage response in Drosophila. Mol Biol Cell 27: 1740-1752, 2016.
20. Grosch M, Grüner B, Spranger S, Stütz AM, Rausch T, Korbel JO, Seelow D, Nürnberg P, Sticht H, Lausch E, et al: Identification of a Ninein (NIN) mutation in a family with spondyloepimetaphyseal dysplasia with joint laxity (leptodactylic type)-like phenotype. Matrix Biol 32: 387-392, 2013.

21. Olson JE, Wang X, Pankratz VS, Fredericksen ZS, Vachon CM, Vierkant RA, Cerhan JR and Couch FJ: Centrosome-related genes, genetic variation, and risk of breast cancer. Breast Cancer Res Treat 125: 221-228, 2011.

22. Zheng L, Song A, Ruan Y, Chen L, Liu D, Li X, Guo H, Han J, Li Y, Tian X and Fang W: Genetic polymorphisms in AURKA, BRCA1, CCNE1 and CDK2 are associated with ovarian cancer susceptibility among Chinese Han women. Cancer Epidemiol 37: 639-646, 2013.

23. Sobin LH, Gospodarowicz MK and Wittekind C (eds): Union for International Cancer Control (UICC). TNM Classification of Malignant Tumours, 6th edition. Wiley-Liss, New York, NY, 2002.

24. Sambrook J, Fritsch EF and Maniatis T: Molecular cloning: A laboratory manual. Cold Spring Harbor Laboratory Press, Cold Spring Harbor, NY, 2001.

25. Higasa K, Miyake N, Yoshimura J, Okamura K, Niihori T, Saitsu H, Doi K, Shimizu M, Nakabayashi K, Aoki Y, et al: Human genetic variation database, a reference database of genetic variations in the Japanese population. J Hum Genet 61: 547-553, 2016.

26. Couch FJ, Wang X, Bamlet WR, de Andrade M, Petersen GM and McWilliams RR: Association of mitotic regulation pathway polymorphisms with pancreatic cancer risk and outcome. Cancer Epidemiol Biomarkers Prev 19: 251-257, 2010.

27. Zhang X, Chen MH, Wu X, Kodani A, Fan J, Doan R, Ozawa M, Ma J, Yoshida N, Reiter JF, et al: Cell-type-specific alternative splicing governs cell fate in the developing cerebral cortex. Cell 166: 1147-1162.e15, 2016.

28. Wedemeyer WJ, Welker E and Scheraga HA: Proline cis-trans isomerization and protein folding. Biochemistry 41: 14637-14644, 2002. 